\title{
A CRÍTICA DE MARX À EPISTEMOLOGIA DE RICARDO
}

\section{Marx's criticism of Ricardo's epistemology}

\author{
Jadir Antunes \\ Doutor em Filosofia pela Unicamp e Professor do Mestrado em Filosofia da Unioeste, Toledo, \\ PR - Brasil, e-mail: jdiant@yahoo.com.br
}

\begin{abstract}
Resumo
Este artigo pretende mostrar, a partir da análise de duas passagens importantes de Teorias da Mais-valia e de O Capital, a crítica de Marx a Ricardo e sua precariedade epistemológica. Segundo Marx, as confusões conceituais de Ricardo devem-se ao fato de ele não levar o processo de abstração e purificação do pensamento para além das interferências enganosas da concorrência e dos dogmas e representações vulgares do capitalista prático. Para Marx, o pensamento verdadeiramente científico é o pensamento que se eleva acima destas falsas representações e que pensa o verdadeiro como atividade do pensamento e não da representação e intuição sensíveis.
\end{abstract}

Palavras-chave: Marxismo; Crítica da economia política; Teoria marxista do conhecimento.

\section{Abstract}

This article intends to show, from an analysis of two important passages from Theories of Surplus Value and Capital, Marx's criticism of Ricardo and his epistemological precariousness. According to Marx, Ricardo's conceptual confusions are due to the fact that he does not carry on the abstraction process and thought 
purification beyond the deceiving interferences of competition as well as the dogmas and vulgar representations of the practical capitalist. For Marx, the truly scientific thought is thinking which raises itself above those falses representations and thinks the true as a thinking activity, not as a representation or a sensible intuition activity.

Keywords: Marxism; Critique of political economy; Marxist theory of knowledge.

\section{Apresentação}

Neste artigo, pretendemos mostrar a crítica de Marx a Ricardo em dois textos importante de Teorias da Mais-valia (capítulo XVII do Tomo Segundo) e de $O$ Capital (Seção Terceira do Livro Terceiro). Na primeira parte do artigo, procuramos mostrar a crítica de Marx às concepções de Ricardo acerca da possibilidade, ou não, de uma cisão entre produção e consumo surgida a partir da cisão entre mercadoria e dinheiro, crítica exposta em Teorias da Maisvalia. Na segunda parte, procuramos mostrar a crítica às concepções de Ricardo sobre o problema da lei da queda tendencial da taxa de lucro exposta no Terceiro Livro de $O$ Capital. Por último, procuramos mostrar a base dos erros de Ricardo e a relação destes erros com a questão da abstração e purificação do pensamento das representações emanadas da concorrência e da vida cotidiana.

Marx, como sabemos, sempre teve muito respeito pela idoneidade científica de Ricardo. As críticas de Marx surgem, por isso, devido a duas circunstâncias importantes. A primeira circunstância surge do fato de Ricardo não se desvencilhar completamente dos dogmas de Say, com sua falsa concepção sobre o equilíbrio automático do mercado, e dos dogmas emanados da chamada circulação mercantil simples. As falsas concepções de Say e Ricardo, segundo Marx, explicam-se pelo caráter burguês do pensamento de ambos. Como burguês, dirá Marx, será natural que as concepções de Ricardo não avancem para muito além dos fenômenos que se mostram na superfície da concorrência e do empirismo da vida prática.

A segunda circunstância se deve ao fato de que Ricardo não leva o processo de abstração e análise aos níveis mais profundos exigidos pelo pensamento teórico. Segundo Marx, os erros epistemológicos de Ricardo - como o erro de confundir o lucro industrial com a própria mais-valia e não como uma 
fração desta, ou, ainda, como uma forma mistificada da mais-valia - devem-se ao fato de Ricardo não levar o processo de abstração e purificação do pensamento para além das interferências enganosas da concorrência.

Nosso artigo pretende, assim, mostrar, a partir dos dois textos já indicados, esta crítica de Marx a Ricardo e sua precariedade no processo de abstração e de elevação do pensamento acima das falsas concepções emanadas da atividade ordinária do mercado e dos negócios.

\section{A crítica à teoria do equilíbrio de mercado}

No capítulo XVII do Tomo II do Livro Teorias Sobre a Maisvalia, Marx critica as concepções de Ricardo sobre a crise capitalista. Ricardo, seguindo os princípios da "Lei de Say,"1 como sabemos, considera que sob o capitalismo é impossível ocorrer uma superprodução generalizada de mercadorias e uma dissociação, também generalizada, entre oferta e procura de produtos. Para Ricardo, é impossível superprodução ou, pelo menos, pletora geral no mercado, porque este se baseia na troca de produtos por produtos, no equilíbrio metafísico entre vendedores e compradores. De acordo com Ricardo, ${ }^{2}$ influenciado por Jean Baptiste Say, "produtos são sempre trocados por produtos ou por serviços; dinheiro é apenas o meio por que se efetua a troca" (MARX, 1980, p. 935. MEW, 1967, p. 500).

Marx critica este ponto de vista em Ricardo porque ele esquece que;

o objetivo direto da produção capitalista não é o valor de uso, mas o valor de troca e em especial o incremento da mais-valia. Este é o motivo que impulsiona a produção capitalista, e é um primor de concepção a que, para escamotear as contradições [Widersprüche] da produção capitalista, omitelhe a base e faz dela uma produção dirigida para o consumo imediato dos produtores" (MARX, 1980, p. 931. MEW, 1967, p. 495).

\footnotetext{
Este princípio da economia vulgar defende a falsa concepção de que toda produção cria naturalmente sua própria demanda. Vide a obra de MIGLIOLI, J. Acumulação de capital e demanda efetiva. São Paulo: T. A. Queiroz, 1987, listada ao final nas Referências, que em seus primeiros capítulos apresenta uma boa síntese deste falso postulado.

2 RICARDO, David. Princípios de economia política e tributação. São Paulo: Nova Cultural, 1996. Todas as citações de Marx referem-se a esta obra de Ricardo. Todas as vezes que me referir a Ricardo, estarei me referindo a esta obra. Reproduzo no artigo somente as citações do próprio Marx extraídas diretamente da obra de Ricardo.
} 
Marx critica Ricardo por não perceber que o produto capitalista não é um mero produto ou bem, que o produto capitalista é, sim, uma mercadoria e como tal, está cindido pela contradição entre valor de uso e valor. Enquanto mercadoria, o valor de uso de determinado produto só pode se realizar na esfera do consumo mediante sua metamorfose em valor de troca. Caso esta metamorfose não se realizar, fica sem se realizar o fim da própria produção de mercadorias, ou seja, a formação e valorização do valor. Como a esfera da produção está separada da esfera do consumo pela esfera da circulação de mercadorias, a conversão do produto em dinheiro pode não ocorrer e, por isso, submeter-se aos jogos de acaso do mercado. Neste, a pressa e a necessidade do portador de dinheiro de converter este último em mercadoria pode não coincidir com a pressa e a necessidade do portador da mercadoria, surgindo, assim, desta antítese, a possibilidade de uma crise para a mercadoria.

Ricardo erra em suas concepções acerca da natureza contraditória da sociedade capitalista porque com ele, segundo Marx, "a mercadoria, que encerra a oposição [Gegensatz] entre valor de troca e valor de uso, transforma-se em mero produto (valor de uso), e em consequiência a troca de mercadorias, em simples troca de produtos, de meros valores de uso" (MARX, 1980, p. 937. MEW, 1967, p. 501). Com a falsa concepção de que mercadoria e produto, ou mercadoria e bem, são sinônimos e equivalentes entre si, Ricardo escamoteia, inconscientemente, a primeira condição da produção capitalista: "que o produto tem de ser mercadoria, de se representar por isso em dinheiro [Geld darstellen] e passar pelo processo de metamorfose" (MARX, 1980, p. 937. MEW, 1967, p. 501-502). A metamorfose do dinheiro em mercadoria é uma condição fundamental e impossível de ser evitada para que a mercadoria atinja a esfera do consumo e, assim, realize seu valor de uso. Se a mercadoria não se metamorfosear em dinheiro, todo o processo cai por terra. Mas, para Ricardo, esta metamorfose não é um problema para a mercadoria, já que, em sua concepção, produtos sempre se trocam por outros produtos e o dinheiro não é o fim do processo, mas, sim, mero elo mediador da metamorfose da mercadoria em bem de consumo.

Ricardo não apenas emprega em sua teoria sobre a sociedade capitalista palavras incorretas, segundo Marx, como as palavras produto e bem, como emprega, ainda, a palavra serviço quando deveria empregar a palavra trabalho. Esta confusão gramatical, segundo Marx, é produto do apego excessivo de Ricardo à linguagem vulgar de Say e dos economistas práticos.

No uso da palavra serviço, segundo Marx: 
se omite a característica específica do trabalho assalariado e de seu valor de uso - a saber, acrescer o valor das mercadorias pelas quais se troca, produzir mais-valia - e em consequiência a relação particular por meio da qual dinheiro e mercadoria se convertem em capital (MARX, 1980, p. 937. MEW, 1967, p. 502).

Assim como as palavras bem e produto expressam apenas o aspecto útil da mercadoria e abstraem o aspecto contraditório dela, isto é, o aspecto que faz dela a portadora do valor de troca, também a palavra serviço expressa o trabalho humano sob o aspecto exclusivo de trabalho útil criador de valor de uso - para Max, aspecto acessório na produção capitalista, já que esta está voltada para a valorização do valor -, e se omite, assim, o aspecto do trabalho como trabalho genérico e abstrato criador de valor e mais-valor.

Para Marx, o engano provocado pela substituição da palavra mercadoria pelas palavras bem e produto, assim como a substituição da palavra trabalho pela palavra serviço, faz com que Ricardo escamoteie, inconscientemente, o fundamento mais básico da produção capitalista: a fissura entre mercadoria e dinheiro e o desdobramento desta, na fissura entre trabalho criador de valores, uso, o trabalho concreto, e trabalho valorizador do valor, o trabalho abstrato.

Com esta confusão, Ricardo esquece o princípio mais básico e fundamental da economia capitalista:

a existência do produto como mercadoria, a duplicação [die Verdopplung] da mercadoria em mercadoria e dinheiro, os daí oriundos elementos da dissociação [Trennung] na troca das mercadorias, enfim, a relação do dinheiro ou mercadorias com o trabalho assalariado. (MARX, 1980, p. 937. MEW, 1967, p. 502).

Como Ricardo não dá importância a este aspecto contraditório da mercadoria, ele também não dá importância ao fato de que o trabalho na sociedade capitalista não existe como trabalho em sua forma natural, isto é, como trabalho concreto e útil materialmente. Ricardo não compreende, segundo Marx, que na sociedade capitalista o trabalho existe sob uma forma socialmente determinada, sob a forma de trabalho assalariado, isto é, sob a forma de trabalho alienado em relação aos meios de produção. Ricardo compreende, segundo Marx, apenas os caracteres mais aparentes e sensíveis do trabalho, aqueles caracteres visíveis ao homem comum, esquecendo de analisá-lo em seus aspectos sociais e abstratos visíveis apenas ao pensamento. 
A confusão de Ricardo em não distinguir claramente os dois aspectos do trabalho humano, o trabalho em sua forma natural-particular como criador de valores de uso e o trabalho em sua forma social-genérica como criador de valor é comum a todos os grandes economistas de seu tempo. Este erro, segundo Marx, deve-se à circunstância de Ricardo entender, falsamente, que a sociedade capitalista não se diferencia em seus fundamentos de nenhuma outra forma de produção anterior a ela, deve-se à circunstância de Ricardo imaginar que a forma de produção capitalista é uma forma natural e não uma forma socialmente determinada. Por esta circunstância, Ricardo confunde as determinações sociais da mercadoria com suas determinações naturais, submetendo as primeiras ao domínio das segundas. Para Marx, a análise correta deveria chegar a um resultado exatamente inverso ao de Ricardo: na sociedade capitalista, as determinações naturais da produção estão inteiramente subordinadas às determinações de ordem social, isto é, às determinações emanadas do trabalho em sua forma abstrata-genérica e à valorização sem fim do valor (MARX, 1988a, p. 76. MEW, 1962a, p. 96). ${ }^{3}$

Para Ricardo, seguindo Say, sob o regime capitalista certo produtor só produz se tiver o propósito de consumir ou vender, e só vende se tiver o propósito de comprar outra mercadoria que de imediato lhe seja útil ou contribua para produção futura. Ao produzir, acredita Ricardo, o produtor torna-se necessariamente o consumidor de seus próprios bens ou o comprador e consumidor das mercadorias de outra pessoa, que de posse de boas informações não produzirá jamais uma mercadoria para a qual não há procura. Esta concepção, na opinião de Marx, é um palavrório pueril que fica bem para Say, mas não para Ricardo. Marx critica esta concepção falsa de Ricardo, concepção emprestada de Say, porque, segundo ele:

Nenhum capitalista produz para consumir o produto. E quando falamos da produção capitalista, o certo é dizer que 'ninguém produz com o propósito de consumir seu produto', mesmo se emprega partes dele no

\footnotetext{
3 Apesar destas confusões, Ricardo foi o único, na concepção de Marx, dentre todos os economistas clássicos, inclusive em relação a Adam Smith, a avançar conscientemente para além das confusões e trivialidades do capitalista prático e da economia vulgar, que atribuem o valor à utilidade do produto. Mesmo que a análise da grandeza do valor e sua relação com o trabalho humano seja muito precária em Ricardo, ela, porém, é, segundo Marx, a melhor análise produzida pela Economia Política Clássica. Sobre isto, vide notas 31 e 32, do próprio MARX, Carl. O capital. Livro Primeiro. Tradução de Régis Barbosa e Flávio R. Kothe. 3. ed. São Paulo: Nova Cultural, 1988a. v. 1.
} 
consumo industrial. E aqui se trata do consumo individual. Esqueceu-se antes que o produto é mercadoria. Agora, esquece-se até a divisão social do trabalho. (MARX, 1980, p. 938. MEW, 1967, p. 503).

No raciocínio de Ricardo está subjacente a idéia metafísica do equilíbrio entre compra e venda, equilíbrio que só considera a unidade e não a separação dos diferentes momentos da compra e venda. Nesta idéia de equilíbrio, a venda, M-D, converte-se imediatamente em D-M, a compra. Esta metafísica não aceita a possibilidade de M-D-M se dissociar no tempo e no espaço em duas fases contrapostas como M-D e D-M. Marx critica Ricardo por desconhecer a possibilidade desta dissociação do mercado e com ela a possibilidade de surgir uma crise de superprodução de mercadorias originadas da cisão da mercadoria em mercadoria e dinheiro. Em Ricardo, segundo a crítica de Marx, o dinheiro, D, é apenas um meio de troca e de circulação das mercadorias e nunca um elemento que expressa a riqueza em sua forma abstrata e geral que pode ser desviado do circuito imediato de compra e venda e fixarse como tesouro fora da circulação. Ricardo, preso às categorias da esfera da circulação mercantil simples, não consegue compreender a inversão desta esfera na esfera capitalista da circulação de mercadorias, onde o dinheiro se converte em fim do processo e não mais em meio dele.

Para Marx, o dinheiro é não só o meio pelo qual se efetua a troca, "mas também o meio por que a troca de produto por produto se dissocia em dois atos, um do outro independentes [becomes dissolved into two acts, independent of each other $=$ em inglês no original $]$, além de distantes no tempo e no espaço" (MARX, 1980, p. 939-940. MEW, 1967, p. 504-505).Em Ricardo, contudo, dirá Marx, a falsa concepção do dinheiro como meio de circulação decorre de ele apoiar-se apenas na determinação quantitativa do valor de troca, isto é, de ele acreditar que o valor de troca é apenas igual a dada quantidade de trabalho. Preso ao empirismo da vida cotidiana que confirma aos nossos sentidos que o valor de troca é mesmo apenas certa quantidade de produtos que se trocam por outros produtos, preso à precariedade de sua epistemologia e de seu baixo grau de abstração, Ricardo não consegue perceber a determinação qualitativa do valor de troca, a determinação não quantificável pelo empirismo e por nossos sentidos, "isto é [Ricardo não consegue compreender], que o trabalho individual tem de se configurar em trabalho social geral, abstrato, o que só se dá por meio de sua alienação [Entäußerung]" (MARX, 1980, p. 940. MEW, 1967, p. 505).

Ricardo, com sua concepção baseada na idéia de que a produção capitalista é uma produção mercantil simples e voltada para a produção de meios de satisfação humana, não vê diferenças importantes entre o produto enquanto 
mercadoria e o produto enquanto bem. Marx critica Ricardo por isso, que pensa que a forma mercadoria do produto não importa na análise dos fundamentos do capitalismo, que pensa que a circulação capitalista da mercadoria só formalmente difere da troca de produtos e da circulação mercantil simples, que pensa que o valor de troca é mera forma efêmera do intercâmbio material e o dinheiro, portanto, mero meio formal de circulação. Este ponto de vista de Ricardo, segundo Marx, "reduz-se de fato a seu pressuposto de que o modo de produção burguês é o modo absoluto, em conseqüência, o modo de produção sem determinação característica mais precisa, sendo, por conseguinte, sua especificidade puramente formal" (MARX, 1980, p. 962. MEW, 1967, p. 528).

A concepção ricardiana de que o modo de produção capitalista constitui-se na forma absoluta de produção e que as diferenças entre mercadoria e dinheiro são diferenças meramente formais omite a determinação mais característica, precisa e específica da sociedade capitalista: o fato de que ela é uma sociedade onde se produz para valorizar o valor e não para satisfazer as necessidades humanas. A sociedade capitalista não é, como nos modelos baseados na circulação mercantil simples do produto, uma sociedade de produtores independentes que produzem para autoconsumo, mas uma sociedade dividida em classes que se contradizem na produção. O produto mais genuíno do capital não é um mero bem ou mercadoria, mas, essencialmente, mais-valia, o sobreproduto social em sua forma mais universal e abstrata. Ricardo, porém, preso ao empirismo do mercado e às determinações meramente formais da circulação mercantil simples, preso à concepção quantitativa do valor de troca, nunca conseguiu compreender a natureza contraditória do capital, nem a maisvalia como a forma mais superior e abstrata da riqueza. Com essa concepção, Ricardo "não pode admitir que o modo de produção burguês contenha limite [Schranke] para o livre desenvolvimento das forças produtivas, limite [Schranke] que vem à tona nas crises e em outras manifestações como a superprodução - o fenômeno fundamental das crises" (MARX, 1980, p. 962. MEW, 1967, p. 528).

Os erros de Ricardo criticados por Marx nesta passagem de Teorias da Mais-valia decorrem basicamente de ele não compreender a contradição mais básica e fundamental da produção capitalista, a contradição que fundamenta e impulsiona todas as outras contradições: a contradição contida no interior da mercadoria, a contradição entre valor de uso e valor expressa na contradição entre mercadoria e dinheiro. Estes erros se devem, sobretudo, ao precário processo de abstração de Ricardo, ao seu excessivo apego aos dogmas do pensamento de Say e do economista prático, à sua incapacidade para se desvencilhar das falsas concepções emanadas da concorrência e da 
superficialidade da vida cotidiana e de sua incapacidade para se elevar a formas superiores e mais abstratas de pensamento.

\section{A crítica à teoria da queda da taxa de lucro}

Outra questão importante ligada ao problema dos limites do capitalismo estudada por Ricardo é a questão da queda tendencial da taxa de lucro. Para Ricardo, a queda na taxa de lucro é sempre resultado de uma queda na força produtiva do trabalho agrícola e, por isso, resultado de uma alta geral dos salários. Esta concepção de Ricardo esconde, na concepção de Marx, a circunstância de que a queda na taxa de lucro vem sempre, e necessariamente, acompanhada de uma elevação, tanto da massa de mais-valia quanto, principalmente, da taxa de exploração do trabalhador pelo capital.

Na Seção Terceira do Livro Terceiro de O Capital, Marx faz questão de criticar esta concepção de Ricardo porque, conforme havia demonstrado nas seções I e II do Livro Terceiro de $O$ Capital, o lucro é nada mais que a forma invertida e mistificada da mais-valia, e a taxa de lucro é nada mais do que a forma invertida e mistificada em que se apresenta, ao nível da esfera sensível e da consciência do economista burguês, a taxa de mais-valia, a taxa de exploração do trabalhador. Lucro e taxa de lucro para Marx são, assim, nada mais do que formas enganosas e transmutadas da mais-valia e da taxa de mais-valia.

Nas palavras de Marx (1988b, p. 27. MEW, 1962b, p. 46):

A mais-valia recebe a forma transmutada de lucro [verwandelte Form des Profits] [...] O lucro, tal como o temos inicialmente ante nós, é, portanto, o mesmo que a mais-valia, apenas numa forma mistificada [mystifizierten Form], que, no entanto, brota necessariamente do modo de produção capitalista.

O grande defeito da análise de Ricardo sobre o processo de formação da mais-valia foi o de nunca tê-lo analisado em sua forma pura. Ricardo, preso ao empirismo do mercado e às concepções do capitalista prático que espera um lucro igual para todas as partes do capital adiantado, nunca conseguiu conceber a mais-valia em sua forma pura porque nunca levou o processo de abstração e análise às suas últimas conseqüências, porque sempre analisou a mais-valia na forma poluída e deturpada do lucro industrial, porque nunca conseguiu conceber o lucro do capital como uma forma derivada e secundária da mais-valia, como uma forma que só poderia ser inteiramente 
compreendida depois de compreendida a natureza da mais-valia em seu estado puro. Ricardo não soube desvendar a lei da queda tendencial da taxa de lucro, apresentando-a como uma lei oriunda da Natureza e da queda marginal da produtividade do solo, por que, segundo Marx, "nunca apresentou a mais-valia separada do lucro e o lucro em forma pura, separadamente de suas partes constantes autonomizadas entre si - como lucro industrial, lucro comercial, juros, renda fundiária" (MARX, 1988b, p. 155-156. MEW, 1962b, p. 223-224).

A compreensão da taxa de lucro só é possível, segundo Marx, depois de compreendidas as leis gerais da mais-valia. Para Marx, o lucro é uma forma derivada da mais-valia, é a parte desta que fica com o capitalista industrial. Ricardo, preso à análise desta forma derivada da mais-valia, nunca conseguiu ir além e compreender a mais-valia em sua forma pura e independente de suas formas derivadas. Para Marx, no entanto, o caminho metodologicamente correto para se compreender a taxa de lucro começa pela compreensão da mais-valia em sua forma pura. Somente depois de compreendida a mais-valia nesta forma geral e abstrata torna-se possível, segundo ele, a compreensão teórica da taxa de lucro e dos movimentos do capital nas esferas da concorrência e da distribuição da mais-valia. Ricardo, contudo, não avança para além da teoria geral do valor, não consegue perceber que o lucro industrial é apenas uma forma modificada e aparente de maisvalor apropriado pelo capitalista da indústria. Para Marx, "é fácil compreender a taxa de lucro, tão logo se conheça as leis da mais-valia. Pelo caminho inverso [como fez Ricardo] não se entende ni l'un, ni l'autre [nem um, nem outro em francês no original]" (MARX, 1988a, p. 168. MEW, 1962a, p. 230).

Ricardo, preso às concepções emanadas da vida cotidiana, apreende na análise da mais-valia apenas os fenômenos visíveis aos nossos sentidos e experiências individuais. O lucro é a forma mistificada e invertida da mais-valia porque com ele todas as partes do capital adiantado aparecem como fontes do valor e da valorização do valor. Para Marx, a única parte do capital adiantado que valoriza efetivamente o capital global é a parte adiantada com salários, isto é, a parte adiantada com capital variável. O lucro, assim, não compõe toda a maisvalia, ele é a parte mais visível dela, é a parte que se fixa no bolso do capitalista instalado na indústria e que se manifesta diretamente à consciência sensível dos agentes da produção. A mais-valia é a forma pura e genérica da riqueza capitalista. Ela se divide, ou se decompõe, em diversas partes, como lucro industrial, lucro do comerciante, juros e renda da terra. Essas partes são diretamente visíveis à consciência sensível dos capitalistas práticos e seus economistas. A mais-valia, contudo, não é perceptível diretamente aos sentidos destes homens, ela é 
perceptível apenas ao pensamento e à investigação teórica, apenas àqueles que se desprendem destas formas precárias de pensamento e a compreendem em seu sentido conceitual e genérico. Caso a mais-valia fosse percebida em sua forma pura e genérica diretamente pelos nossos sentidos, o homem comum poderia percebê-la sem o auxílio da Filosofia e da Economia Política, sendo estas dispensáveis na sociedade moderna. O capitalista prático e o economista vulgar têm, inclusive, um interesse consciente em esconder a mais-valia, neste sentido genérico, da sociedade e dos trabalhadores e apresentá-la no sentido confuso de lucro industrial. O verdadeiro, como afirma Marx várias vezes ao longo de $O$ Capital, é invisível aos nossos sentidos. "Mais-valia e taxa de mais-valia são, em termos relativos, o invisível e o essencial a ser pesquisado, enquanto a taxa de lucro e, portanto, a forma da mais-valia como lucro se mostram na superfície dos fenômenos" (MARX, 1988b, p. 32. MEW, 1962b, p. 53). Ricardo não consegue se elevar ao nível da compreensão da mais-valia em sua forma pura e, por isso, invisível aos nossos sentidos, porque nunca conseguiu não apenas se desprender por completo das concepções do capitalista prático, mas, sobretudo, porque nunca levou o processo de abstração e elevação do pensamento aos seus níveis mais desenvolvidos, porque permaneceu, em certo sentido, preso ao empirismo e à tradição teórica inglesa de sua época.

Como lucro e taxa de lucro são formas mistificadas da mais-valia e da taxa de mais-valia ao nível da realidade sensível, aparente e imediata do mercado, a queda na taxa de lucro aparece, então, de maneira ainda mais mistificada, como a forma de manifestação invertida do aumento da taxa de mais-valia. A queda da taxa de lucro vem sempre acompanhada de uma elevação na produtividade do trabalho social, e não o contrário, como concebia Ricardo. A queda na taxa de lucro, a queda relativa da massa de mais-valia em relação ao capital global empregado, esconde, segundo Marx, todas as determinações essenciais nas quais se fundamenta a acumulação capitalista: aumento absoluto da massa de mais-valia, aumento absoluto da taxa de exploração sofrida pelos operários, aumento absoluto da força produtiva do trabalho, aumento absoluto da concentração da riqueza em sua forma abstrata de um lado e, de outro, aumento cada vez mais absoluto da pobreza no pólo que produz esta riqueza.

Porque a taxa de lucro e sua queda nas crises escondem todas as determinações mais internas e fundamentais do capital, Marx não se cansa de dizer que ela é apenas uma forma mistificada e enganosa de manifestação, sob bases capitalistas, do crescimento absoluto da produtividade do trabalho social, do crescimento absoluto da massa de riqueza produzida e do crescimento absoluto da exploração no interior da classe operária. Marx insiste em afirmar, 
por isso, que a queda na taxa de lucro é um mero fenômeno, uma mera forma de manifestação de algo mais fundamental e oculto à nossa percepção sensível. Quando Marx expõe a lei da queda tendencial da taxa de lucro, nunca a apresenta, portanto, como causa das crises, mas, sim, como a forma de manifestação de algo mais fundamental e não-perceptível imediatamente aos nossos sentidos. A queda na taxa de lucro é nada mais que "uma expressão peculiar (ein eigentümlicher Ausdruck) ao modo de produção capitalista para o desenvolvimento progressivo da força produtiva social do trabalho" (MARX, 1988b, p. 155. MEW, 1962b, p. 223).

Também o progressivo decréscimo relativo do capital variável em relação ao capital global, em outras palavras, também o aumento da composição orgânica do capital, aumento que está na base da queda da taxa de lucro, "é igualmente [diz Marx], apenas outra expressão (nur ein andrer Ausdruck) para o progressivo desenvolvimento da força produtiva social do trabalho" (MARX, 1988b, p. 155. MEW, 1962b, p. 222). Diz ainda Marx que tanto a elevação da taxa de mais-valia quanto a queda da taxa de lucro "são apenas formas específicas em que se expressa de maneira capitalista a crescente produtividade do trabalho (sind nur besondre Formen, worin sich wachsende Produktivität der Arbeit kapitalistisch ausdrückt)" (MARX, 1988b, p. 173. MEW, 1962b, p. 250). Diz ainda mais uma vez Marx: "o decréscimo proporcional do capital variável e o aumento do capital constante, embora ambas as partes cresçam absolutamente, é, como se disse, apenas outra expressão (nur ein andrer Ausdruck) para a produtividade aumentada do trabalho" (MARX, 1988b, p. 157. MEW, 1962b, p. 226).

Diz ainda Marx, criticando Ricardo: "o decréscimo tendencial da taxa de lucro está ligado a uma elevação tendencial da taxa de mais-valia, portanto, do grau de exploração do trabalho" (MARX, 1988b, p. 173. MEW, 1962b, p. 250). É esta elevação tendencial da taxa de mais-valia que se manifesta, de modo invertido, como uma queda tendencial da taxa de lucro e que fica escondida atrás das categorias da economia política de Ricardo, que Marx não se cansa de criticar.

Nada mais errado, segundo Marx, do que explicar a queda da taxa de lucro a partir de uma elevação dos salários, como explicava Ricardo. "A taxa de lucro não cai porque o trabalho se torna mais improdutivo, mas porque se torna mais produtivo" (MARX, 1988b, p. 173. MEW, 1962b, p. 250). Marx repete ainda: "a taxa de lucro cai não porque o trabalhador seja menos explorado, mas porque, em relação ao capital empregado, utiliza-se em geral menos trabalho" (MARX, 1988b, p. 177. MEW, 1962b, p. 256). 


\section{A crítica à precariedade epistemológica}

A indiferença do capitalista prático e seus economistas políticos, entre eles Ricardo, com as diferenças reais entre mais-valia e lucro e taxa de mais-valia e taxa de lucro, a indiferença destes frente à determinação da lei do valor é, segundo Marx:

[...] a melhor prova de que o capitalista prático, preso à luta concorrencial (Konkurrenzkampf) e que de modo algum penetra através de suas formas aparentes (Erscheinungen), é necessariamente incapaz de reconhecer, através das aparências (Schein), a essência íntima (innere Wesen) e a configuração íntima (innere Gestalt) desse processo. (MARX, 1988b, p. 125. MEW, 1962b, p. 178).

Marx compreende que esta incapacidade do pensamento para superar a força dilacerante e enganosa do fetiche das relações de mercado não pode ser encontrada apenas entre os capitalistas práticos, prisioneiros do empirismo do mercado, mas pode, ainda, ser encontrada entre os economistas políticos mais conscientes da burguesia, como Smith e Ricardo, homens que ele tanto respeitava.

Apesar das repetidas críticas a Ricardo, Marx, contudo, não cansa de elogiar seu senso científico e sua honestidade intelectual. Seus elogios se estendem, ainda, a Adam Smith, pai da Economia Política, porque, segundo Marx, Smith "procura de início apreender a coisa em sua conexão interna (innren Zusammenhang) e depois, na forma inversa (umgekehrten Form), como ela aparece na concorrência (konkurrenz erscheint)" (MARX, 1980, p. 537. MEW, 1967, p. 100). Porém, Smith "comporta-se ingenuamente com ambas as idéias que nele se entrecruzam (kreuzen), sem perceber a contradição (Widerspruche)" (MARX, 1980, p. 537. MEW, 1967, p. 100). O erro de Smith consistia em não perceber a diferença importante entre estes dois níveis de investigação: o nível aparente e externo e o nível interno e essencial da realidade.

Smith, segundo Marx:

ora investiga as conexões internas (innren Zusammenhang) das categorias econômicas ou a estrutura oculta (verborgnen Bau) do sistema econômico burguês. Ora junta a essa pesquisa as conexões (Zusammenhang) tais como se exteriorizam na aparência dos fenômenos (Erscheinungen) da concorrência e se manifestam, portanto, ao observador não científico (unwissenschaftlichen Beobachter) e, do mesmo modo, ao que na prática está preso e interessado no processo da produção burguesa (MARX, 1980, p. 597-598. MEW, 1967, p. 162). 
A fraqueza de Smith para ir além das categorias econômicas emanadas da concorrência, categorias como preço, lucro e taxa de lucro, residia, segundo Marx, na sua incapacidade para isolar os fenômenos aparentes surgidos na esfera do mercado dos fundamentos ocultos da sociedade capitalista e visíveis apenas à investigação teórica e ao processo de abstração do pensamento.

Smith, assim, apesar de avançar suas análises para além do senso não-científico do homem comum, como, por exemplo, em sua análise do trabalho como fundamento do valor, acaba se confundindo com este mesmo senso comum ao confundir a determinação do valor, em certos momentos de seu pensamento, com o valor de uso do produto. Smith, como sabemos, ora concebe, acertadamente, que o valor de uma mercadoria está determinado pela quantidade de trabalho humano despendido em sua produção e ora concebe, erroneamente, como o homem comum, que o valor está determinado pela utilidade do produto.

Ricardo, ao contrário de Smith, segundo Marx, já consegue perceber melhor os dois níveis de existência de um conceito e diferenciar a forma pura e conceitual de uma coisa de sua forma empírica, aparente e enganosa.

Ricardo; "de maneira consciente abstrai da forma da aparência da competição, para apreender as leis como tais” (MARX, 1980, p. 537. MEW, 1967, p. 100). Contudo, cabe criticá-lo, "por um lado, por não avançar nem ser conseqüente bastante na abstração [...], por outro lado, por conceber a forma fenomenal [Erscheinungsform], de maneira imediata e direta, como prova ou representação das leis gerais, sem explicá-la" (MARX, 1980, p. 537. MEW, 1967, p. 100). Ricardo, apesar de compreender a diferença de níveis no conceito de uma coisa, é muito rápido, segundo Marx, em querer provar que os fenômenos expressam algo mais oculto e fundamental. Marx critica Ricardo, por exemplo, por passar muito rápido da teoria do valor-trabalho à teoria da renda da terra. Esta passagem rápida e sem muitas mediações, esta pressa em provar os argumentos sem desenvolvê-los pacientemente, é, segundo Marx, um dos grandes defeitos da epistemologia de Ricardo e flanco aberto a seus adversários partidários da teoria do valor-utilidade.

Assim mesmo, Marx elogia Ricardo por ter ido além de Smith no processo de abstração. Critica-o, porém, devido à insuficiência científica de sua análise, a seu apego aos dogmas do capitalista prático e por não levar o processo de abstração a níveis mais elevados. "A insuficiência [de Ricardo] se revela no modo de apresentação (Darstellungsart) (meramente formal) e, ademais, leva a resultados errôneos, porque omite os necessários elos intermediários e procura de imediato provar a congruência entre as categorias econômicas" (MARX, 1980, p. 597. MEW, 1967, p. 161-162).

O erro metodológico básico de Ricardo consistiu em não submeter adequadamente à crítica as categorias descobertas na superfície aparente dos 
fenômenos; consistiu em não procurar encontrar novas e mais profundas determinações que revelassem todos os elos mediadores que ligam a superfície visível da concorrência com os fundamentos ocultos do capital.

O erro básico de Smith e Ricardo consistiu, no fundamental, em não fazerem uma crítica consequiente das categorias e representações aparentes do capitalista prático, em não negarem suficientemente os fenômenos enganosos da concorrência, pois:

Na concorrência [diz Marx] aparece, pois, tudo invertido (es erscheint also in der Konkurrenz alles verkehrt). A figura acabada (fertige Gestalt) das relações econômicas, tal como se mostra na superfície, em sua existência real e, portanto, também nas concepções mediante as quais os portadores e os agentes dessas relações procuram se esclarecer sobre as mesmas, difere consideravelmente, sendo de fato o inverso (verkehrt), o oposto (gegensätzlich), de sua figura medular (Kerngestalt) interna, essencial mas oculta (wesentlichen aber verhüllten), e do conceito (Begriff) que lhe corresponde (MARX, 1988b, p. 153. MEW, 1962b, p. 219).

A insuficiência teórica de Ricardo para explicar as conexões externas do capital sem desvendar suas conexões internas deve-se à circunstância de ter se agarrado demasiadamente e sem consciência às falsas representações do capitalista prático. Este, segundo Marx, preso à luta concorrencial e à atividade empresarial cotidiana, é incapaz de penetrar seu pensamento no interior dos fenômenos que se mostram na superfície do mercado, é necessariamente incapaz de reconhecer, por trás das aparências, a configuração interna do processo de valorização do valor.

Na concorrência, as leis internas da produção da mais-valia aparecem como leis externas que emanam da própria concorrência e não da relação contraditória entre as classes no interior do processo de produção imediato da mais-valia. A concorrência desfigura o sistema de preços, ocultando a circunstância de que o processo de formação dos preços e do lucro está determinado pela lei do valortrabalho. Na concorrência tudo aparece invertido porque nela o preço de produção aparece como um preço posto pelo gênio do capitalista individual que acresce ao preço de custo a taxa de lucro média e, assim, chega ao preço final da mercadoria.

Segundo Marx (1988b, p. 152. MEW, 1962b, p. 219):

O que a concorrência não mostra é a determinação de valor (Wertbestimmung), que domina (beherrscht) o movimento da produção; esses são os valores que estão atrás (hinter) dos preços de produção e que, em última instância (letzter Instanz), os determinam (bestimmem). 
A concorrência aparece, portanto, para Marx, como a fonte última de onde emanam todas as deformações e incompreensões do funcionamento real e interno da produção capitalista, como a fonte de todos os fetiches misteriosos que enganaram tanto a Ricardo quanto a seu mestre Smith, para Marx, como dissemos, os mais sérios e honestos teóricos burgueses do capital.

Apesar das críticas de Marx a Ricardo e seus falsos postulados, postulados estes emprestados de Say, Ricardo não deve, de modo algum, ser confundido com este último e a economia vulgar. A economia vulgar se caracteriza por aceitar acriticamente as falsas representações produzidas na consciência do capitalista prático e de converter estas representações em teoria e apologia do sistema capitalista. Segundo Marx, a economia vulgar se caracteriza por se mover apenas dentro do nexo aparente e exterior da concorrência, limitando-se "a sistematizar, pedantizar e proclamar como verdades eternas as idéias banais e presunçosas que os agentes da produção burguesa formam sobre seu mundo, para eles o melhor possível" (MARX, 1888a, p. 76. MEW, 1962a, p. 96).

Segundo Marx, Ricardo caracteriza-se por ser um cientista sério que procura honestamente investigar os nexos internos das condições de produção burguesa. A circunstância de ele não conseguir rastrear e entender estes nexos em toda a sua imanência e necessidade deve-se, principalmente, à sua precariedade epistemológica e, de modo algum, como para a economia vulgar e J. B. Say, de seu interesse consciente de esconder da sociedade e dos trabalhadores a essência íntima e irracional da sociedade capitalista.

\section{Conclusão}

O erro básico de Ricardo - para Marx o mais completo, profundo e honesto teórico do capitalismo -, consistiu em não superar adequadamente as determinações contidas na esfera ilusória e exterior da concorrência, em não adentrar de modo rigoroso na análise interna do capital, em não analisar com profundidade as relações de produção no interior da fábrica, em contentar-se mais com a natureza da distribuição da mais-valia entre capitalistas e donos da terra do que com a natureza da produção dessa mais-valia, em contentar-se mais com a análise da concorrência, da ação recíproca dos vários capitais individuais entre si, e menos com a análise do capital em si mesmo, do capital em sua forma pura e abstraída da concorrência, do capital em sua relação com a classe operária, instância interna e fundamental do capital. 
Os erros de Ricardo decorrem do fato de ele ser burguês em pensamento e, como tal, de levar a sério as representações e vulgaridades do capitalista prático preso à concorrência e à vida cotidiana dos negócios. Para Marx, o pensamento verdadeiramente científico é o pensamento que se eleva acima destas falsas representações da vida ordinária e que pensa o verdadeiro como atividade do pensamento e não da representação e intuição sensíveis.

\section{Referências}

MARX, Karl. Das Kapital. Karl Marx \& Friedrich Engels: Werke - Band 23. Berlim: Dietz Verlag, 1962a.

Das Kapital. Karl Marx \& Friedrich Engels: Werke - Band 25. Berlim: Dietz Verlag, 1962b.

Theorien Über den Mehrwert. Marx-Engels: Werke. Band 26.2. Berlim: Dietz Verlag, 1967.

Teorias da mais-valia. Tradução de Reginaldo Sant'Anna. São Paulo: Difel, 1980.

O capital. Livro Primeiro. Tradução de Régis Barbosa e Flávio R. Kothe. 3. ed. São Paulo: Nova Cultural, 1988a. v. 1.

O capital. Livro Terceiro. Tradução de Régis Barbosa e Flávio R. Kothe. 3. ed. São Paulo: Nova Cultural, 1988b. v. 4.

MIGLIOLI, J. Acumulação de capital e demanda efetiva. São Paulo: T. A. Queiroz, 1987.

RICARDO, David. Princípios de economia política e tributação. São Paulo: Nova Cultural, 1996.

Recebido: 23/12/2007

Received: $12 / 23 / 2007$

Aprovado: $15 / 01 / 2008$

Approved: 01/15/2008 